\title{
Extending the Diffusion of Innovation Theory to Predict Smartphone Adoption Behaviour Among Higher Education Institutions' Lecturers in Nigeria
}

\author{
Adeola A. Ayodele ${ }^{1} \quad$ Chibuike B. Nwatu ${ }^{2}$ Olise, Moses Chigbata ${ }^{3}$ \\ 1.Department of Marketing, Nnamdi Azikiwe University Awka, Nigeria \\ 2.Department of Marketing,Enugu State University of Science and Technology, Enugu, Nigeria \\ 3.Department of Marketing,Nnamdi Azikiwe University, Awka, Nigeria
}

\begin{abstract}
With the rise in the number of ICT-enabled devices in Nigeria and considering the relevance and importance of these devices in effective teaching, it becomes legitimate and inevitable to understand the key predictors of smartphone adoption among lecturers in the higher education institutions (HEIs). While extant literatures are gorged with such investigations, the majority of Sub-Saharan African contexts are grossly under-researched. Using this as a point of departure, this paper seeks to answer these questions: what are the predictors of smartphone adoption among the university lecturers? And how do these identified predictors influence smartphone adoption among university lecturers? Since smartphone is a new technological device and its adoption as a teaching-enabled device is different from its traditional adoption for communication, the main objective of this paper is to empirically investigate the predictors of smartphone adoption among Nigerian university lecturers. The study was based on the lecturers of Nnamdi Azikiwe University, Awka, Anambra State, Nigeria. Data were collected using questionnaire based on multistage sampling technique of 284 respondents. Factor analysis and multiple regressions were used for data reduction and hypotheses testing respectively. Analyses of data reveal that personal experience, relative advantage, job relevance, triability, complexity and price were the predicators of smartphone adoption. The findings have serious implications for smartphone retail management among others.
\end{abstract}

Keywords: Adoption Behaviour, Complexity, Higher Education Institutions, Job Relevance, Nigeria, Personal Experience, Price, Relative Advantage, Smartphone, Triability.

DOI: $10.7176 / \mathrm{EJBM} / 12-5-02$

Publication date: February $29^{\text {th }} 2020$

\section{Introduction}

The pervasive nature of information and communication technologies (ICTs) has brought about tremendous technological, social, political and economic transformation, which has eventuated in a network society built around ICTs (Yusuf, 2005 as cited in Ntemana \& Olatokun, 2012). Considering the relevance of education in nation building and ever-increasing quest for university education particularly in Nigeria and sub-saharan Africa at large, the engagement of ICTs in the teaching-learning process becomes important (Ntemana \& Olatokun, 2012). According to Isaacs (2001) as cited in Ntemana \& Olatokun (2012), the adoption of ICT-enabled device by the teachers will enhance effective teaching. Issues such as good course organization, effective class management, content creation, self-assessment, self-study collaboration learning, task-oriented activities, and effective communication between the actors in the teaching-learning process and research activities will be enhanced by the use of ICT-based device (Ntemana \& Olatokun, 2012).

A relatively new ICT-enabled device is the smartphone, a mobile phone with advanced features beyond those of ordinary GSM phones (Putzer \& Park, 2010). It is an information technology tool capable of accessing the internet at broadband speed ranging from $144 \mathrm{kbps}$ to $2 \mathrm{mbps}$ or more. The smartphone emerged in 2000 (Putzer \& Park, 2010) and Nigerians buy $41 \%$ of Smartphone sold in Africa since its arrival in 2006 (Revmatas, 2013). This connotes that adoption of smartphone is at the initial stage in Nigeria compared to over 129 million active subscribers presently in Nigeria (NCC, 2014). A driving force for the adoption of smartphone is their portability and wireless connectivity features. These features, coupled with the standard communication capabilities provided by smartphone, help individuals access to e-mail and the internet at a go (Putzer \& Park, 2010). Despite the importance and relevance of smartphone to the academic world especially the university education, the actual number of lecturers who are competent in smartphone use and the extent to which they optimize smartphone for teaching and other functions in Nigeria Universities is unknown. In addition, the attributes that could influence the adoption of smartphone among university lecturers in South-Eastern Nigeria remain unidentified, at least empirically, creating a gap that this study hopes to fill in supporting Nnamdi Azikiwe University's success in its vision for qualitative higher education. The need to adopt Smartphone in our education sector as a tool to facilitate learning is imperative. In a study carried out by Oye, Aiahad and Abrahim (2010), they discovered that smartphone adoption among Nigerian lecturers is alarmingly low despite the fact that Nigerians buy $41 \%$ of smartphone sold in Africa (Revmatas, 2013). Smartphone can be adopted by a lecturer to improve class quizzing, improve real- 
time conversation via internet and project supervision (Carey, 2012).

Studies have been conducted to underpin innovation factors and adoption rate (Rogers, 1983; 1995; 2003, Jang, 2010; Chong, 2006; Putzer \& Park, 2013). Ntemana and Olatokun (2012) conduct empirical investigation on influence of attributes of diffusion of innovation on lecturer's use of ICTs in University of Lesotho. Also, Ayodele and Ifeanyinchukwu (2016) studied the factors influencing smartphone purchase behaviour among young adults in Nigeria. However, none of these studies empirically investigate the factors that influence smartphone adoption among university lecturers and mostly alien to the typical Nigerian context. More so, no study has been done in South-Eastern Nigeria that explored the effect of innovation diffusion attributes on the basis of individual perspectives. Thus, the study of adoption of smartphone based on individual perspective of the technology among university lecturers could tremendously contribute to the body of educational technology and marketing knowledge in Nigeria. The main objective of the study is to empirically investigate the factors that influence Smartphone adoption among university lecturers. In specific terms, the study sought to:

1. Identify those factors that influence smartphone adoption among university lecturers.

2. Determine the degree to which these identified factors influence smartphone adoption among university lecturers.

3. Discuss the implications of the above and make recommendations based on the findings.

\section{Literature Review}

According to Rogers (1995), there exist five basic innovation attributes and each of these attributes is somewhat empirically interrelated with the other four, but they are conceptually different (Roger, 1995). The five attributes of innovations are: (1) relative advantage (2) compatibility (3) complexity (4) Triability and (5) observability. Rogers (2003) specified five primary variables which interact to show how individual adoptions combine to represent diffusion. In this current study, our focus was on the five key variables that have effects on both individual and organization at large.

\subsection{Relative Advantage}

This is an individual's perception that an innovation is better off in comparison to similar ideas, products, practices (Ntemana \& Olatokun, 2012). It can also be seen as how the individuals perceive an innovation with regard to its predecessor- if they view the innovation as having more benefits than the previous (Ekebom, 2012). The degree of relative advantage is a measure of economic profitability, social prestige, or other benefits (Rogers, 2003). In the word of Chong (2006), relative advantage is said to be the perceived benefits and impacts relative to the existing practice or system.

\subsection{Compatibility}

This is the degree to which an innovation is adjudged to be inconsistent with the existing values (Tidd, 2006). Compatibility is seen as the extent to which the innovation is consistent with the available values, previous experiences and needs of prospective adopters (Rogers, 2003). An innovation might be perceived to be technically or financially superior in achieving a given task, but it may not be adopted, if the prospective adopters see it as irrelevant to their needs (Aghaunor \& Fotoh, 2006). If smartphone is perceived by lecturers as compatible with the existing work practices, environments, and overall objective, it will be more likely to be adopted. As for compatibility, Smartphone was easy to adopt as an improvement to previous mobile phones, giving new enhanced solutions to existing needs. (Ekebom, 2012).

\subsection{Complexity (Ease of Use)}

Rogers (2003) defines complexity as the extent to which an innovation is perceived as difficult to use and understand. Generally, innovations that are simpler for potential users to understand will be adopted more rapidly than those which require development of new skills and knowledge (Tidd, 2006). The harder the concept of an innovation to grasp, the slower the rate of adoption (Ekebom, 2012). Complexity for smartphone is very low as it makes phone usage easier although with its new attributes (primarily touch screen which is quite new for the entire industry), it may take a short while for a user to adopt the new way of usage.

\subsection{Triability}

Chong (2006) defines triability attribute as the extent or degree to which an innovation can be pilot tested, regardless of the high start-up costs. In the word of Tidd (2006), triability is the extent to which an innovation can be experimented within a limited basis. Innovation that gives room for triability will be adopted quickly than those which cannot (Tidd, 2006). If an early version of a Smartphone with limited functionality could be offered for potential users (lecturers) to experiment with for free, the adoption rate would probably increase (Ekebom, 2012). 


\subsection{Observability}

Rogers (2003) defines observability as the degree to which the results or outcomes of an innovation are made visible to others. Visibility of an innovation stimulates word-of-mouth and helps to increase the adoption rate (Ekebom, 2012). The philosophy behind observability is similar to unspoken peer pressure: if influential individual posses an innovation, the observer is more likely to adopt it as well (Ntemana \& Olatokun, 2012). The easier it is for others to see the benefits of an innovation, the more likely it will be adopted (Tidd, 2006). Ntemana and Olatokun (2012) opined that observability results to a special threshold at the point where an innovation becomes so eclectic and or desirable in a culture that even those who would not normally be a user of an innovation consider adopting the product.

\subsection{Innovation}

Innovations are described as the new technical products, scientific knowledge, application methods and tools that facilitate problem solving for potential adoption. Different adopters perceive and access innovation in a variety of ways (Tolba \& Mourad, 2010). Rogers $(1983 ; 1995 ; 2003)$ suggest that innovations analysis should be made in the context of the potential adopters' own perspective and situation; conversely to emphasize the subjective nature of innovations. Robertson and Gatignon (2000) as cited in Tolba \& Mourad (2010), suggest that this subjective approach is likely to differ from the descriptions of innovations, which are provided by a manufacturer or distributor.

\subsection{Adoption of Innovation}

This can be designated as the degree to which a firm or an individual is successfully using an innovation. This construct borrows four concepts and definitions from diffusion and integration studies by Massetti and Zmud (1999) as cited by Chong (2006). Thus, the construct adoption of Smartphone among university lecturers combines the notions of volume, diversity, breadth and depth.

Volume: The proportion of academic exercise derived from the use of Smartphone

Diversity: The varieties of academic exercises or work derived from the use of Smartphone.

Breadth: The extent to which adoption of Smartphone has helped interactions with other lecturers.

Depth: The level of usage of Smartphone for academic related activities.

\subsection{Other Innovation Factors}

According to Kwon and Zmud (1987) as cited in (Putzer \& Park, 2010), innovation attributes can be studied more effectively by the adjustment of research factors related to DoI theory. They identified personal demographics, job relevance and personal experience as diffusion of innovation attributes that can affect extent of adoption at individual. Personal demographic has been an important factor in diffusion, adoption and gratifications studies (Kim, 2003). According to Li et al. (1988) as cited in (Kim, 2003), he posited that consumers who are better educated, have a higher income will adopt online buying than those who are not. According to Putzer and Park (2010), personal demographics comprise the participant's age, gender and personal traits. In the study conducted on community nurses in some parts of the USA by Putzer and Park (2010), they found out that job relevance was a significant innovation attribute, they opine that if a nurse believed a Smartphone assisted with improving patient care, he or she would more readily adopt it. Personal experience includes factors such as participant's computer background, education and literacy. Harman and Koohang (2003) as cited in (Putzer \& Park, 2010), revealed a positive relationship of personal demographics and personal experience to innovation adoption. In addition, price was found to be a significant innovation factor that influences extent of adoption of innovation (Ekebom, 2012). In his study conducted on private consumers' view point on adoption of smartphone, Ekebom (2012) found out the pricing of an innovation has a heavy relational weight as one of the motivators in making the innovation adoption decision.

\section{Theoretical Framework}

This study was based on two theories namely; diffusion of innovation theory (DoI) by Rogers $(1983,1995 ; 2003)$ and Kwon and Zmud (1987) model of diffusion and adoption. This study decided to adapt these models because they capture innovation attributes influencing any new technology. Diffusion of Innovation Theory (DOI) is a theory of how, why and at what rate new ideas and technology spread through cultures, operating at the individual level (Oliveria \& Martins, 2010). Kwon and Zmud (1987) model of diffusion and organizational adoption focus on adoption of innovations by individuals. In their framework, Kwon and Zmud (1987) define three contextual factors that may impact on stages of IT implementation. They are: job relevance, personal demographics and personal experience.

\section{Empirical Review}

Many researchers have studied Diffusion of Innovation in general and Smartphone in particular regarding the 
extent of adoption by users. A review of some of these works is presented. Rogers (as cited by Ekebom, 2012), asserted that the innovation attributes as seen by individuals, help to explain their different extent of adoption. Also, Rogers opines that if an innovation is perceived to be more beneficial than previous innovation the extent of its adoption will be faster. This view is supported by Jang (2010); Chong (2006) and Putzer and Park (2010). Furthermore, in the work done by Tidd (2006), he found out that the greater the perceived relative advantage, the faster the extent of adoption. He further asserts that incentives may be used to promote the adoption of an innovation, by increasing the perceived relative advantage of the innovation, subsidizing trials or reducing cost of incompatibility. In a study conducted by Jang (2010) in South Korea on RFID adoption among 171 companies, it was found that perceived benefit (Relative advantage) is significantly related to the extent of RFID use. Also, in the study conducted by Chong (2006) among 115 SMEs in Australia, relative advantage was found to be significantly related to the extent of adoption of electronic commerce with t-value of 2.947 and coefficient of 0.301 . However, in the study conducted by Putzer and Park (2010) among 200 practising community nurses in the South eastern United States, relative advantage was not listed as one of the independent variables of innovation attributes. In the word of Ekebom (2012), an idea or innovation that is compatible with the values and norms of a social system will be adopted easily and faster, because adopting a non-compatible innovation requires adopting a new set of social values and norms, which could take longer time. Putzer and Park (2010) found that compatibility has the strongest relationship to attitude towards using a Smartphone with the beta value of (0.79) and t-value of (11.22). However, in the study carried out by Ntemana and Olatokun (2012) in the National University of Lesotho among 213 lecturers, it was found that compatibility does not contribute to attitude towards an innovation adoption. But the work done by Aghaunor and Fotoh (2006) on e-commerce adoption among Nigerian commercial banks found out that perceived compatibility is the fourth factor affecting adoption of e-commerce. Perceived complexity or ease of use have been extensively studied by IT researchers, several studies discover significant relationships between complexity (perceived ease of use) and use intentions (Vlyke et al., 2014). Complexity had been found also to influence e-government adoption Murali, Wernys and Raduan (as cited in Bojei \& Hoo, n.d). However, Putzer and Park (2010) omitted the variable in their study. Rogers (1995) proposed that the complexity of an innovation, as perceived by members of a social system, is negatively related to its rate of adoption. Further, Rogers asserts that some innovations are clear in their meaning to potential adopters whereas others are not. In order to support the findings of Rogers, Aghaunor and Fotoh (2006) cited in Chwelos et al. (2002), that complexity is a strong inhibitor of extent to adopt innovation. They concluded that a high level of perceived complexity negatively impacts innovation adoption. Therefore, in this study we took the alternative view of this construct by Rogers (1995) and Aghaunor and Fotoh (2006), and hypothesized that if an innovation is easy to use, it is more likely to be adopted, this is in support of Ntemana and Olatokun (2012). We support them because of the similarity of their study to ours. Triability as an innovative attribute was found to be positively related to adoption of innovation (Rogers, 1995; 2003). Chong (2006) found that triability of e-commerce does not have significant relationship with the extent of deployment by Australian SMEs. Triability was found to have a beta value of ($0.240)$ and t- value of (-2.315) respectively. This is supported by the work of Ntemana and Olatokun (2012), they found that triability and compatibility do not contribute to attitude towards adoption of innovation. This variable was however, omitted by Putzer and Park (2010). Observability attribute was generalized to be positively related to innovation adoption (Rogers, 1995; 2003). This generalization is supported by the work of Chong (2006) on ecommerce adoption by Australian SMEs when she found that observability is positively related to e-commerce adoption with beta value of (0.267) and t-value of (2.466) respectively. Also, in the work of Putzer and Park (2010), observability was found be positively related to innovation adoption but not as strong as compatibility and job relevance .Kwon and Zmud (cited in Putzer \& Park, 2010), suggested that information technology might be studied more effectively by adjusting research factors related to DoI theory with application research. The innovation attributes of personal demographics, personal experience and job relevance were added into our model, also an innovation attribute called triability which was removed from the Putzer and Park (2010) model was added. Also, in the work done by Ekebom (2012) on adopting a mobile phone innovation among selected mobile phone users in Helsinki found out that too high price can seriously impair the adoption of an innovation. He further submits that adoption could be increased by offering low-priced tying deals. From the above literature review, we hypothesize as follow:

Ho: Relative advantage, complexity, compatibility, triability, observability, price of smartphone, relevance of smartphone to job, personal experience and demographics do not positive and significant influence on smartphone adoption among lecturers.

\section{Materials and Methods}

Survey research design was adopted in this study-this consists of asking questions, collecting and analyzing data from supposedly representative members of the population at a single point in time with a view to determining the current status of that population with respect to one or more variables under investigation (Okeke, Olise \& Eze, 2012). The population of this study comprises all full-time academic staff of Nnamdi Azikiwe University, Awka 
main campus except those either on sabbatical leave or managerial position. This population is known (finite). The population size of this study is 984 lecturers (UNIZIK Directorate of Academic Planning, 2014). Since the population of study is finite (known), the researchers employed Taro Yamani's formula to determine the sample size. The sample size is calculated thus:

$n=\frac{N}{1+N(e)^{2}} @ 5 \%$ error margin and arrived at 284 Lecturers. This forms the sample size. Moreover, Bourley's Proportional Allocation formula was employed to administer the questionnaire copies among the sample selected. The formula is stated thus,

$n_{A}=\frac{n^{1}\left(n_{o}\right)}{N}$

Where; $n_{A}=$ Allocated proportion

$n^{1}=$ Size of each population segment

$n_{o}=$ sample size

$\mathrm{N}=$ Total population size

Since the population of the study is finite (known) and has a sampling frame, the researchers employed stratified random sampling technique. This was adopted because of the heterogeneous nature of the population. The researchers divided the population into homogeneous subsets (faculties) and then simple random sampling procedure was used to select respondents from each subset for inclusion into the sample. Proportionate stratified sampling was employed because every faculty is represented in the sample according to its proportion in the parent population. Structured questionnaire was adopted as the instrument for data collection. Questionnaire was divided into two sections. Section B of the questionnaire comprised questions on the demographic characteristics of the respondents; Section A collected data on the effect of the nine constructs of innovation attributes and the extent of smartphone adoption among university lecturers. A five-point Likert scale was used in designing the questions. Items on compatibility, observability, job relevance, personal demographics and personal experience were adapted from the work of Kwon and Zmud (1987); and Putzer and Park (2010).Items on relative advantage, complexity and triability were adapted from the work of Ntemana and Olatokun(2012), items on extent of adoption were adapted from the work of Chong(2006) while items on price was designed by the researchers. Cronbach's alpha coefficient was adopted to test the internal consistency of the multiple item scales with a value over 0.70 indicating acceptability. Collected data were first structured into grouped frequency distributions. Factor analysis was used for data reduction which aim at bringing out the parsimonious few variables that can absorb other variables and, any factor loading below 0.5 was deleted while any factor loading above 0.5 was retained (Hair, Bush \& Ortinau, 2006). Multiple regressions were used to test the significance of the hypotheses earlier formulated. Multiple regressions provide a means for identifying predicators of a particular dependent variable on the basis of statistical criteria. Mainly, the statistical tool indicates which independent variable is the best predicator, the second-best predicator and so on (Ntemana \& Olatokun, 2012). For our study, multiple regressions was found to be the most appropriate analytical tools as it helped identify the most parsimonious set of predictors (i.e. innovation attributes) and their effect on extent of smartphone adoption behaviour.

\section{Hypotheses Testing}

In order to test the hypotheses, stepwise multiple regressions were employed. The following tables are the results of that process, using the constructs personal experience, price, complexity, compatibility, personal demographics, relative advantage, triability, job relevance and observability as independent variables and smartphone adoption behaviour as dependent variables.

Table 1: Model Summary

\begin{tabular}{|l|l|l|l|l|l|}
\hline Model & $\mathrm{R}$ & R Square & Adjusted R Square & $\begin{array}{l}\text { Std. Error of the } \\
\text { Estimate }\end{array}$ & Durbin-Watson \\
\hline 1 & $.952 \mathrm{a}$ & .906 & .902 & .31357619 & 1.934 \\
\hline
\end{tabular}

a. Predictors: (Constant), personal experience, price, complexity, compatibility, personal demographics, relative advantage, triability, job relevance, observability

b. Dependent Variable: smartphone adoption behaviour

The model summary of the regression analysis showed a correlation coefficient of .952 which is a positive, very strong correlation. The ${ }^{2}$, i.e. coefficient of determination is 906 , which implies that $90.6 \%$ variation in dependent variable (extent of adoption) is associated with the variation in the independent variables. The DurbinWatson (D- W) statistic that measures multicollinearity, for this study was 1.934 and it is within the range of acceptance; this confirms the absence of redundant variables therefore none of the variables used in the study needs to be deleted. Also the adjusted $\mathrm{R}^{2}$ value of .902 indicates that the numbers of independent variables and the sample size is large enough for a study of this magnitude. Table 9 below shows the analysis of variance (ANOVA) value of the regression analysis and the value is 230.246 which is statistically significant at 0.00 . This implies that the research model is a good-fit. Also, because the value of $\mathrm{p}$ is less than 0.05 , the model is significant. 
Table 2: ANOVA

\begin{tabular}{|ll|l|l|l|l|l|}
\hline Model & & Sum of Squares & Df & Mean Square & F & Sig. \\
\hline \multirow{2}{*}{1} & Regression & 203.761 & 9 & 22.640 & 230.246 & .000 \\
& Residual & 21.239 & 216 & .098 & & \\
& Total & 225.000 & 225 & & & \\
\hline
\end{tabular}

a. Dependent Variable: smartphone adoption behaviour

b. Predictors: (Constant), personal experience, price, complexity, compatibility, personal demographics, relative advantage, triability, job relevance, observability

Table below reveals the standardized Beta coefficients, which give the contributions of each variable to the model. The $t$ and $p$ values show the effect of the independent variables on the dependent variables. Based on the analysis, the following inferences were drawn in relation to the hypotheses.

Table 3: Coefficients

\begin{tabular}{|c|c|c|c|c|c|}
\hline \multirow[t]{2}{*}{ Model } & \multicolumn{2}{|c|}{ Unstandardized Coefficients } & \multirow{2}{*}{$\begin{array}{l}\text { Standardized } \\
\text { Coefficients } \\
\text { Beta }\end{array}$} & \multirow[t]{2}{*}{$\mathrm{T}$} & \multirow[t]{2}{*}{ Sig. } \\
\hline & B & Std. Error & & & \\
\hline (Constant) & 7.217E-017 & .021 & & .000 & 1.000 \\
\hline Relative advantage & .073 & .028 & .073 & 2.626 & .009 \\
\hline Complexity & -.061 & .023 & -.061 & -2.650 & .009 \\
\hline Triability & .067 & .029 & .067 & 2.336 & .020 \\
\hline Price & -.046 & .024 & -.046 & -1.874 & .062 \\
\hline Observability & .002 & .030 & .002 & .074 & .941 \\
\hline Compatibility & -.040 & .033 & -.040 & -1.217 & .225 \\
\hline Job relevance & .071 & .030 & .071 & 2.378 & .018 \\
\hline Personal demographics & .015 & .029 & .015 & .507 & 613 \\
\hline personal experience & .875 & .029 & .875 & 30.505 & .000 \\
\hline
\end{tabular}

a. Dependent Variable: smartphone adoption behaviour

The smaller the value of significance ( $\mathrm{p}$ - value) and the larger the $\mathrm{t}$ - value, the greater the contribution of that predictor. In this model, relative advantage $(\mathrm{t}=2.626, \mathrm{p}=.009<0.05)$, triability $(\mathrm{t}=2.336, \mathrm{p}=.020<0.01)$, job relevance $(\mathrm{t}=2.378, \mathrm{p}=.018<0.01)$, complexity $(\mathrm{t}=2.650, \mathrm{p}=.009<0.05)$, price $(\mathrm{t}=-1.874, \mathrm{p}=.062<0.01)$ and personal experience $(\mathrm{t}=30.505, \mathrm{p}=.000<0.05)$ were all significant predictors of extent of smartphone adoption. From the magnitude of the t- values, we can see that personal experience has the highest effect, follow by relative advantage; job relevance, triability, complexity and price in that order. More so, unstandardized Beta coefficients were calculated because they provide insight into the importance of a predictor in the model. The Beta value for personal experience (.875) indicates that personal experience had the strongest relationship with the extent of adoption of smartphone, while relative advantage showed the next strongest relationship $(\beta=.73)$. The new regression model is stated below:

$$
\begin{array}{r}
\text { Adptn }=a+.073 \text { relad } v+-.061 \text { compl } x+.067 \text { triability }+-.046 \text { price }+.002 \text { obsrv } \\
+-.040 \text { compt }+.071 \text { jbrel }+.015 \text { Perdem }+.875 \text { Perexp }+0.0087
\end{array}
$$

\section{Discussion}

The study provided empirical support for six of the hypotheses. The innovation attributes of personal experience, relative advantage, job relevance, triability, complexity, and price were found to influence the extent of smartphone adoption among university lecturers. The innovation attribute of personal experience was found to be statistically significant in our study. This is in contrast with the findings of Pitzer and Park (2014), who discovered that personal experience was not found to be significant. One possible explanation for this finding may be the relatively less experienced lecturers in our study. The average occupational experience was 6 years. It may be presumed lecturers with less experience may embrace new technologies more. For relative advantage, it was found to be significant. This is consistent with the findings of Jang (2010); Chong (2006); Tidd (2006) and Ekebom (2012). The innovation attribute of job relevance was found to be statistically significant in our study. This is in support of the work done by Putzer and Park (2010) who found out that job relevance had a significant effect on smartphone adoption among nurses. If a lecturer believed a smartphone assisted with improving lecture delivery and other academic works, he or she would be more readily to adopt a smartphone. More so, triability was found to have a significant effect on extent of smartphone adoption among university lecturers. This is in consistent with the findings of Rogers (1995) and Rogers (2003). However, Chong (2006) and, Ntemana and Olatokun (2012) found out that triability did not have any significant effect on adoption of innovation. Also, Putzer and Park (2010) supported the findings of Rogers (1995) and Rogers (2003) when they discovered that a brief trial using a smartphone may positively affects 
a user's attitude towards the universal functions and applicability of a smartphone in a clinical setting. This appears to be mainly true when smartphone technology is new to the user. The innovation attribute of complexity was also found to be statistically significant in our study. This is in consistence with the work done by Vlyke et al., (2014), Wernys and Raduan (1995) as cited in Bojei and Hoo (2010) and Ntemana and Olatokun (2012). However the findings of Rogers (1995) and Aghaunor and Fotoh (2006) contradicted our findings when they discovered that complexity is a strong inhibitor of extent of innovation adoption. Our study found out that price has a significant effect on extent of smartphone adoption. This is in consistence with the finding of Ekebom (2012), when he discovered that adoption of an innovation could be increased by offering low- price tying deals. Observability was found not to have a significant effect in our study. This is in contrast with the findings of Rogers (1995); Rogers (2003); Chong (2006) and Putzer and Park (2010). Also, the innovation attribute of compatibility was found not to be statistically significant on our study. This is contrast with the findings of Ekebom (2012); Putzer and Park (2010) and Aghaunor and Fotoh (2006) but in support the findings of Ntemana and Olatokun (2012). Personal demographics was found not to have a significant effect on the extent of smartphone adoption in our study. This is consistent with the findings of Putzer and Park (2010).

\section{Conclusion and Implications}

This study revealed a valuable adaptation of the innovation constructs especially for adoption of smartphones by university lecturers. Smartphones are capable of changing how education is being delivered majorly because they combine multiple and varied technological functions into a single device that is versatile and portable. Our study provided empirical support that the innovation attributes of relative advantage, complexity, triability, job relevance, price and personal experience have significant effects on smartphone adoption among university lecturers. The findings of this study have important implications for smartphone manufacturers, marketers and university lecturers. For smartphones producers, smartphone should be made to be more user-friendly for academic exercises so that lecturers will see the need to own one and use for various academic works. Since, it was discovered that smartphone is relevant to the lecturers' job, smartphone producers should include educational applications into their phone so as to have competitive advantage over other competitors. Diffusion in the marketing parlance refers to the process and rate of acceptance or rejection of new products by consumers, smartphone marketers should consider the innovation attributes that are significant in this study in the course of marketing the product. Also, these innovation attributes should be considered in the course of introducing the product. The university lecturers should adopt the diffusion of innovation model of this study in the course of adopting a smartphone. More so, smartphone marketers can embark on training and re- training of academic staff of higher institutions on how smartphone can enhance their academic work hence, an increase in the sales of their products. Also, to increase their sales margin, smartphone marketers can engage some lecturers already using smartphones to act as their image makers through word- of - mouth which will invariably help to increase the adoption rate. Furthermore, smartphone should be made more compatible with the existing communication technology for lecturers in order to increase their extent of adopting it.

\section{References}

Aghaunor, L. \& Fotoh, X. (2006). Factors affecting E-commerce adoption in Nigerian Banks. Jankoping International Business School, 1-36.

Aker, J.C. \& Mbiti, I.M. (2009). Mobile Phones and Economic Development in Africa. Journal of Economic Perspective, 1(1) 1-44.

Akuezuilo, E.O. \& Agu, N. (2004). Research and Statistics in Education and Social Sciences. (Millennium edition), Awka, Nuel-Centi Publishers and Academic Press Ltd.

Atkinson, N.L. (2012). Developing a Questionnaire to Measure Perceived Attributes of eHealth Innovations. Washington University School of Medicine Library, Journal of Health Behavior, 31(6), 612-62.

Ayodele, A.A. \& Ifeanyichukwu, C.D. (2016). Factors Influencing Smartphone Purchase behavior among young adults. International journal of recent scientific research, 7(9),13248-13254.

Bojei, J. \& Hoo, W.C (n.d). Factors influencing Repurchase Intention of smartphones. Graduate School of Management, Universiti Putra Malaysia, Selangor, 1-12.

Buabeng-Andoh, C. (2012). Factors Influencing Teachers' Adoption and integration of information and communication technology into teaching: a review of the literature. International Journal of Education and Development Using Information and Communication Technology,8(1), 136-155.

Carey, J. (2012).Teaching with smartphones. Retrieved March, 28th 2014 from Powerful learning Practice, http://www.powerfullearningpractice.com/html

Chemingui, H. \& Ben- Lallonna, H. (2013). Resistance, motivations, trust and intention to use mobile financial services. International Journal of Bank Marketing,31 (7),574-592.

Chong, S. (2006). An Empirical Study of Factors that Influences the Extent of Deployment of E-commerce for small and medium-sized enterprises in Australia. Journal of Theoretical and Applied Electronic Commerce 
Research, 1(2),45-57.

Ekebom, E. (2012). Adoption of Smart phones: Iphone, Research of adopting a mobile phone innovation from private consumers'view point. Master's thesis, Department of Information and Service Economy, Aalto University School of Economics.

Green Electronics Trade-in Company (2013). Smartphones as tools for Education: Getting smart with Smartphone. Retrieved 28th March 2014 from http://www.ecycleBest.com/html

Hair, J.F., Bush, R.P. \& Ortinau, D.J. (2006). Marketing Research. NewYork, McGraw Hill/Irwin.

Ifeanyichukwu, C.D. (2016). Demographic variables and Internet Shopping in Nigeria. International Research Journal of Management, IT \& Social Sciences, 3(7).

Jang, S. (2010). An Empirical Study on the Factors influencing RFID Adoption and Implementation. Management Review: An International Perspective, 5(2),55-73.

Kwon, T.H \& Zmud, R.W. (1987). Unifying the Fragmented Models of Information Systems Implementation. In J.R. Boland, and Kirshheim (eds), Critical Issues in Information Systems Research, NY, John Willey,227251.

Lafreniere, K.C, Hunter, M. G. \& Desphande, S. (2011). Comparing and Prioritizing the factors affecting Purchase Decisions in Innovation adoption in a post-secondary Educational Setting. Journal of Information, Information technology and Organisations, 6, 15-39.

Li, C.S., Shea, P. \& Picket, A.M. (2005). Increasing Access to Higher education: a study of the diffusion of online teaching among 913 College Faculty. International Review of Research in Open and Distance Learning, ISSN: $1492-3831$.

Ntemana, T.J. \& Olatokun, W. (2012). Analyzing the influence of diffusion of innovation attributes on lecturers' Attribute Toward Information and Communication Technologies. An Interdisciplinary Journal on Humans in ICT Environments, 8(2),179-197.

Ogunlesi, T. \& Busari, S. (2012). Seven ways mobile phones have changed lives in Africa. CNN International retrieved on $28^{\text {th }}$ March 2014 from http: www.CNNinternational.com

Okeke, T.C; Olise, M.C. \& Eze, G. A. (2013). Research Methods in Business and Management Sciences. ( $2^{\text {nd }}$ edition), Enugu, Iyke Venture Production.

Oliveira, T. \& Martins, M.F (2011). Literature Review of Information Technology Adoption Models at Firm Level. Electronic Journal of Information Systems Evaluation, 14 (1), 110-121).

Oye, N.O., Aiahad, N. \& Abirahim, N. (n.d).Awareness, Adoption, and Acceptance of ICT Innovation in Higher Education Institutions. International Journal of Engineering Research and Applications (IJERA). ISSN:2248-9622,1(4),1393-1409.

Oyelaran-Oyeyinka, B. \& Adeya, C.N. (2004). Internet Accessing Africa: Empirical Evidence from Kenya and Nigeria. Journal of Telematics and Informatics, 21(1),67-81. http://dx.doi.org/10.1016/So736-5853 (03)

Pankratz, M.; Hallfors, D \& Cho, H. (2002). Measuring Perceptions of Innovation adoption: the diffusion of a federal drug prevention policy. Health Education Research Journal,17(3), 315-326. Doi:10.1093/her/17.3.315.

Putzer, G.J. \& Park, Y. (2010). The Effects of Innovation Factors on Smartphone Adoption among Nurses in Community Hospitals. Perspective in Health Information Management, Winter, 1-20

Revmatas, E. (2013). Nigerians Buy 41 Percent of Smartphones sold in Africa. Tell Magazine, Tuesday $13^{\text {th }}$ August 2014 Retrieved from http://www.tellcommunications.org

Rogers E.M. (1983). Diffusion of Innovations. (3rd edition), NY, the Free press.

Rogers, E.M. (1995). Diffusion of Innovations. (4th edition), NY, The Free Press.

Rogers, E.M. (2003). Diffusion of Innovations. ( $5^{\text {th }}$ edition), NY, the Free press.

Todd, J. (2006). A Review of Innovation Models. Imperial College London, Tanaka Business School.

Tolba, A.H. \& Mourad, M. (n.d).Individual and cultural factors affecting the diffusion of innovation. Journal of International Business and Cultural Studies, 1(1),1-16.

Touch App (2011). How to use smartphones in the classroom-Advice for Teachers. Retrieved $28^{\text {th }}$ March 2014 from http://www.touchapp.co.uk/html

UW Bothell Learning Technologies (2012). Smartphones as Learning Tools. Retrieved 28th March 2014 from http://www.nwbit.org/html.

Vess, B. (2013). Three Simple ways to start using smartphones in the classroom. Edudemic Journal, Retrieved $28^{\text {th }}$ March 2014 from http://www.edudemic.org/html

Yusha'u, M.J. (2013). Using a Smartphone to enhance the quality of teaching. Premium Times. Retrieved $28^{\text {th }}$ March 2014, from http://www.premiumtimes.com/jameclyushau.blogspot.co.uk 